\title{
Description of Pintomyia limafalcaoae and Pintomyia antioquiensis, Two New Species of Phlebotomine Sand Fly (Diptera, Psychodidae) from the Colombian Andes
}

\author{
Marta Wolff, Eunice Aparecida Bianchi Galati*/+
}

Departamento de Biologia, Universidad de Antioquia, Medellin, Antioquia, Colombia *Departamento de Epidemiologia, Faculdade de Saúde Pública, Universidade de São Paulo, Av. Dr. Arnaldo 715, 01246-904 São Paulo, SP, Brasil

Two new species of phlebotomine sand fly from Colombian Andes are described, belonging to the subgenus Pifanomyia of the genus Pintomyia. P. (P.) limafalcaoae sp. nov. for which both sexes are described, is assigned to the series pia while P. (P.) antioquiensis sp. nov., known only from the male, is included in the series verrucarum. The subgenus Pifanomyia is characterized and identification keys presented for the two new species.

Key words: Pintomyia (Pifanomyia) antioquiensis sp. nov. - Pintomyia (Pifanomyia) limafalcaoae sp. nov. - Phlebotominae Psychodidae - taxonomy - Colombian Andes

Two new species of phlebotomine, described below, were captured between December 1997-March 1998, in the province of Montebello, Department of Antioquia, in the Colombian Andes.

\section{MATERIALS AND METHODS}

After clearing by the method described by Forattini (1973) and mounting on microscope slides in Canada balsam medium, the specimens were measured with a Zeiss ${ }^{\circledR}$ eye-piece calibrated according to a standard Zeiss ${ }^{\circledR}$ scale and drawn with the help of an Olympus ${ }^{\circledR}$ clear chamber. All measurements are given in micrometers. The measurements of paratypes are given in parentheses. The species nomenclature is in accordance with Galati (1995).

\section{DESCRIPTION}

Pintomyia (Pifanomyia) limafalcaoae sp. nov. (Figs 1-16)

Holotype (male): total body length 3085 . Whole insect dusky.

Head (Fig. 1): length 375; width 350. Eyes: length 205; width 120 (frontal view). Interocular distance 135. Interocular suture not united with the antennal suture. Clypeus length 125. Antennomere lengths: AIII 380, AIV 160, AV 155, AXV 68 and AXVI 60. Antennal formula AIIIAXV 2; AXVI 0; ascoids simple and short, those on AIV not reaching the middle of the segment (Fig. 3); papilla present on AV (Fig. 4) but absent on AXIII (Fig. 5). Length of the palpomeres: I 38, II 128, III 135, IV 78 V 270; Newstead's spines ( $\mathrm{ca} .7$ ), on median third of palpomere III (Fig. 6) and absent from palpomere II. Labroepipharynx 223 long. Labium with the labial sutures united.

Cervix: ventrocervical sensillae present.

${ }^{+}$Corresponding author: Fax: + 55-11-3081.2108. E-mail: egalati@usp.br

Received 25 May 2001

Accepted 12 December 2001
Thorax: mesonotum length 590. Pleura with 2 proepimeral setae and 12, 13 upper anepisternal setae; absence of setae on the anterior katepisternum margin and the suture between katepimeron and metepisternum. Wing (Fig. 12): length 2170, width 620 . Length of vein sections: alpha 530 , beta 230 , gamma 240 , delta 160 , pi $120, \mathrm{R}_{5} 1340$. Length of femora, tibiae, basitarsi and tarsi II+III+IV+V: foreleg 800, 1020, 640, 800; midleg, missing; hindleg 820, 1450, 800,860 .

Abdomen 2678 long. Tergites II-VII with tergal papillae. Terminalia (Fig. 14): gonostyles 127 long, with 4 and 5 major spines (Fig. 15) and one subterminal seta; the spines having the following disposition: one apical, the upper external on the 4th apical of the structure, the lower external and the internal in the middle of the structure (the gonostyle with 5 spines, the extra spine being implanted between the two external ones). Gonocoxite (250 long x 63 wide), with median tuft of $c a .12$ isolated setae. Paramere simple and concave in the middle of the dorsal margin; dorsal margin length 188 and the ventral margin length 225 , with the setae implanted in the 5th apical. Conical aedeagus, dorsal margin length 77 and ventral margin length 100. Lateral lobe length 254; width 28. Genital pump: 150 long; piston length 117 and chamber length 50. Genital filaments length 430 or 2.87 times length of genital pump. Tip of genital filaments simple (Fig. 13). Cercus 195 long.

Allotype (female): total body length $\mathrm{ca}$. 2870. General coloration as in the male.

Head (Fig. 2): length 380; width 390. Eyes: length 208; width 126 (frontal view). Interocular suture not united with the antennal suture. Interocular distance 135. Clypeus 120 long. Flagellomeres missing. Palpomere lengths: I 38, II 130, III 158, IV 103, V, missing. Newstead's spines (ca. 12), on median 3rd of palpomere III (Fig. 9) and absent from palpomere II. Labroepipharynx 255 long. Cibarium (Fig. 10) with ca. 20 reduced anterior teeth, five posterior teeth and lateral teeth very reduced too, pigment patch and posterior bulge not well developed, arch complete. Pharynx (Fig. 10) unarmed. Labium with sutures united. Maxilla: lacinia (Fig. 7) with 3-4 external teeth disposed in a 
longitudinal row and $c a .13$ internal teeth. Hypopharynx (Fig. 8) with $c a .15$ deep apicolateral teeth.

Cervix: ventrocervical sensillae present.

Thorax: mesonotum 670 long. Pleurae with 2, 4 proepimeral setae and 16 upper anepisternal setae. Absence of the setae on the anterior katepisternum margin and the suture between katepimeron and metepisternum. Wing (Fig. 11): length 2370 and width 730 . Length of vein sections: alpha 600 , beta 260, gamma 270, delta 125, pi 110, R5 1490. Length of femora, tibiae, basitarsi and tarsi II+III+IV+V: foreleg, missing; midleg 800, 1290, basitarsi and tarsi II+III+IV+V, missing; hindleg 900, 1510, 830, 880.

Abdomen length 1820. Tergite VIII without setae.

Spermathecae (Fig. 16) resemble wrinkled vesicles (25 long $\mathrm{x} 23$ wide) with a much smaller apical ring (5 long $\mathrm{x} 12$ wide); smooth individual ducts, 70 long $x 10$ wide; smooth common duct, 145 long x 20 wide. Cercus 150 long.

Collection dates and deposition of material type. Holotype male: Montebello, Antioquia Department, Colom- bia, 23.12.1997; allotype female same locality as holotype, 31.3.1998. Holotype and allotype deposited in entomological collection of the Department of Biology, University of Antioquia, Colombia, both captured by M Wolff \& P Gutierrez with Shannon trap 18:00-20:00 h.

Locality type: Vereda Savanitas, $37 \mathrm{~km} \mathrm{SE}$ of Medellin, $2060 \mathrm{~m}$ above sea level, $05^{\circ} 54^{\prime} 8.4^{\prime \prime} \mathrm{N}$ and $75^{\circ} 31^{\prime} 1.3^{\prime \prime} \mathrm{W}$, in area of humid montaine forest on a rock formation containing small caves.

\section{Pintomyia (Pifanomyia) antioquiensis sp. nov.} (Figs 17-26)

Holotype (male): total body length 2650. Insect predominantly pale brown, with mesonotum darker brown.

Head (Fig. 17): length $353(332,340 ; n=2)$; width 310 (300; $\mathrm{n}=2$ ). Eyes: length 178; width 100 (frontal view) $(160,170$ x 93, 90; $n=2)$. Interocular distance $115(117,123 ; n=2)$. Interocular suture not united with the antennal suture. Clypeus length $115(115 ; n=2)$. Antennomere lengths:

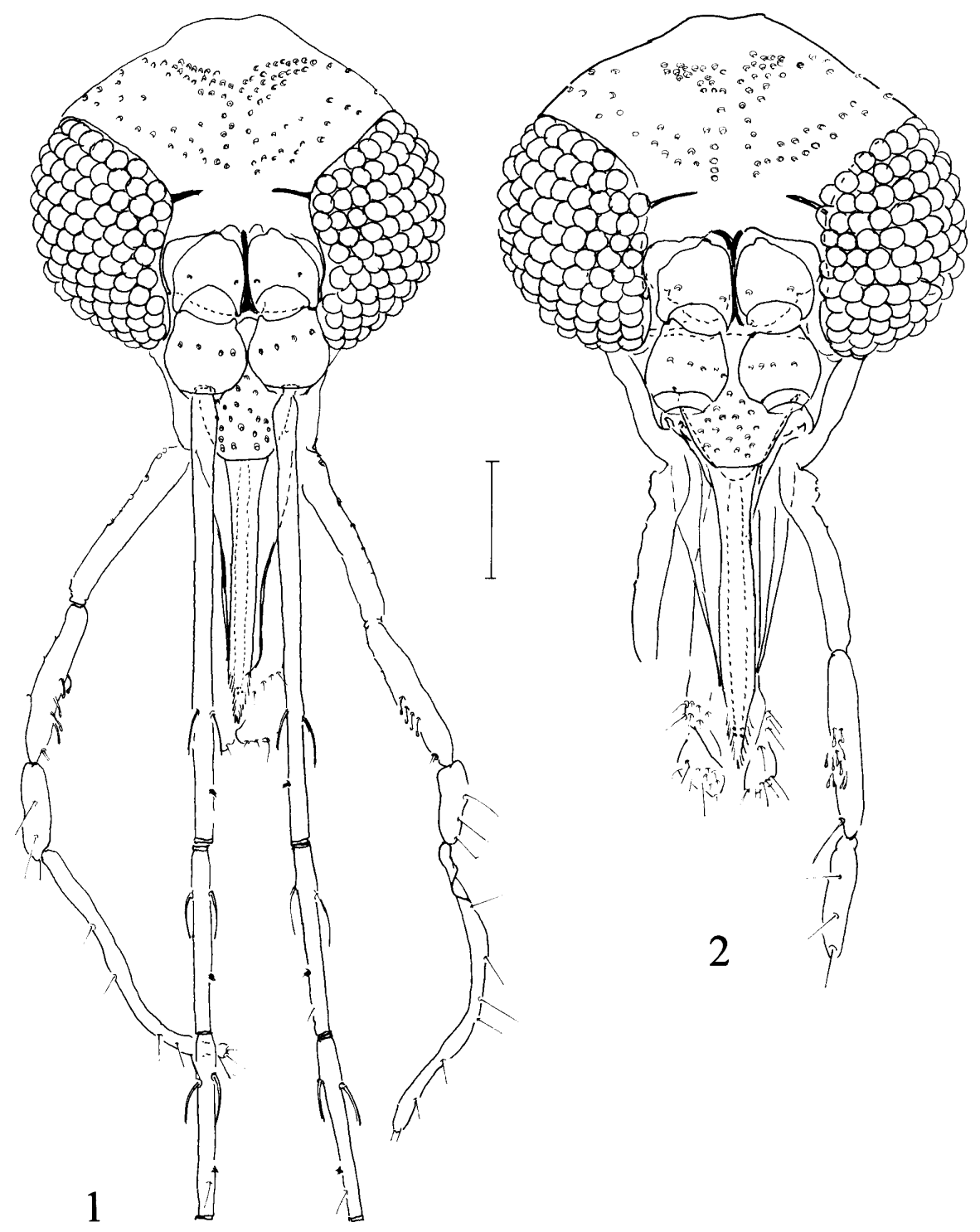

Pintomyia (Pifanomyia) aldafalcaoae sp. nov. holotype male and allotype female - Fig. 1: head male. Fig. 2: head female. Bar $=100 \mu \mathrm{m}$ 
AIII $320(305,325 ; \mathrm{n}=2)$, AIV $128(120,127 ; \mathrm{n}=2), \operatorname{AV} 126$ $(120,127 ; \mathrm{n}=2), \operatorname{AXV} 72(65,75 ; \mathrm{n}=2)$ and AXVI $60(58$, $60 ; \mathrm{n}=2$ ). Antennal formula AIII-AXIV 2; AXV 1, AXVI 0 ; ascoids simple and short, those on AIV reaching the middle of the segment (Fig. 19); papilla present in AV (Fig. 19). AXI-AXIII with medial papilla (Figs 20,21). Length of the palpomeres: I $38(35,37 ; n=2)$, II $165(148,165 ; n=2)$, III $150(138,150 ; n=2)$, IV $122(98,120 ; n=2)$, V 357 ( 305 , $370 ; n=2)$; Newstead's spines on median third of the palpomere III (Fig. 18) and absent in the palpomere II. Labroepipharynx 227 long.

Cervix: ventrocervical sensillae present.
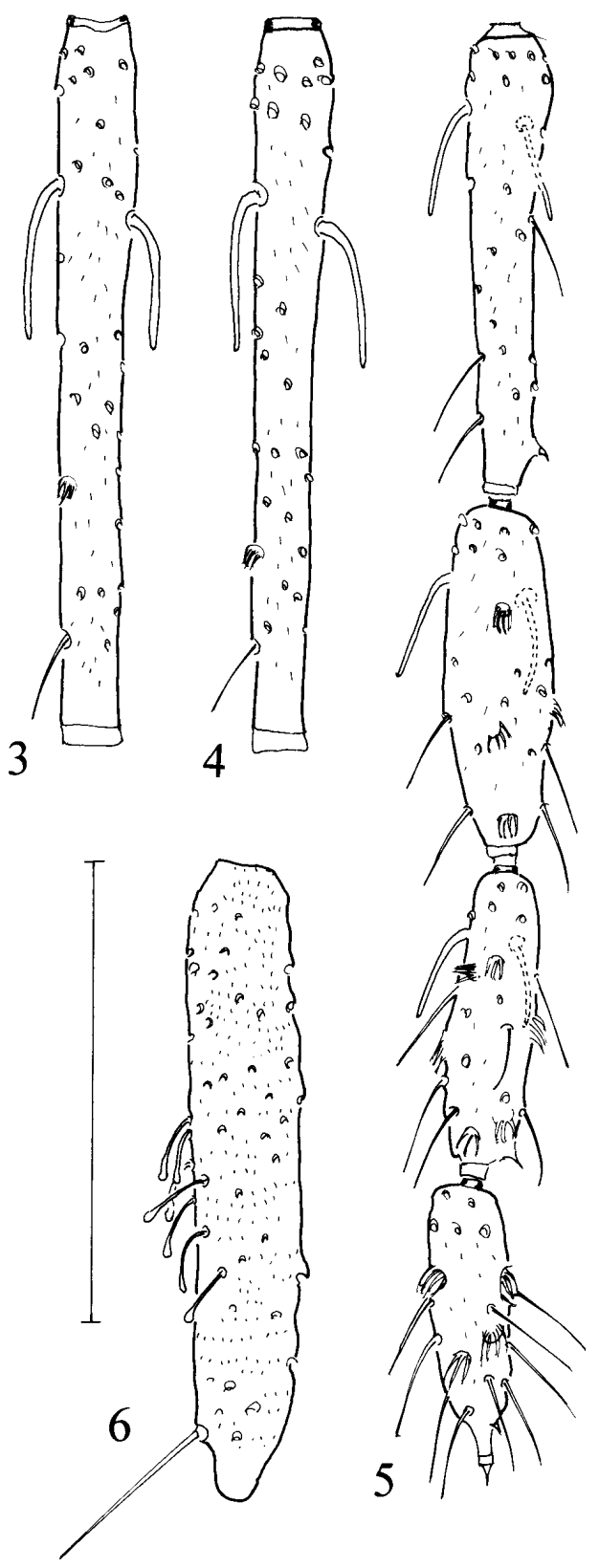

Pintomyia (Pifanomyia) aldafalcaoae sp. nov. Holotype male Fig. 3: antennomere IV. Fig. 4: antennomere V. Fig. 5: antennomere XIII-XVI. Fig. 6: palpomere III. Bar $=100 \mu \mathrm{m}$
Thorax: mesonotum length $500(510,550 ; \mathrm{n}=2)$. Pleura with $1,2(1,2 ; n=2)$ proepimeral setae and $9,11(5-9 ; n=$ 2) upper anepisternal setae; absence of setae on the anterior katepisternum margin and of the suture between katepimeron and metepisternum. Wing (Fig. 22): length $1860(1760,1900 ; \mathrm{n}=2)$ and width $510(480,500 ; \mathrm{n}=2)$. Length of vein sections: alpha $460(400,430 ; \mathrm{n}=2)$, beta $160(160,190 ; \mathrm{n}=2)$, gamma $320(300,320 ; \mathrm{n}=2)$, delta 110 $(60,110 ; \mathrm{n}=2)$, pi $70(110 ; \mathrm{n}=2), \mathrm{R}_{5} 1240(1200,1250 ; \mathrm{n}=$ 2). Length of femora, tibiae, basitarsi and tarsi II+III+IV+V: foreleg, missing; midleg 720, 970, 565, 680; hindleg 750, $1150,640,760$.

Abdomen $1300(1230,1370 ; \mathrm{n}=2)$ long. Tergites IV-VII with tergal papillae. Terminalia (Fig. 24): gonostyle (Fig. 25) 160 long $(150,160 ; n=2)$, with 4 major spines and one subterminal seta; the spines with the following disposition: one apical, the upper external on the 4th apical of the structure, the lower external and the internal before the
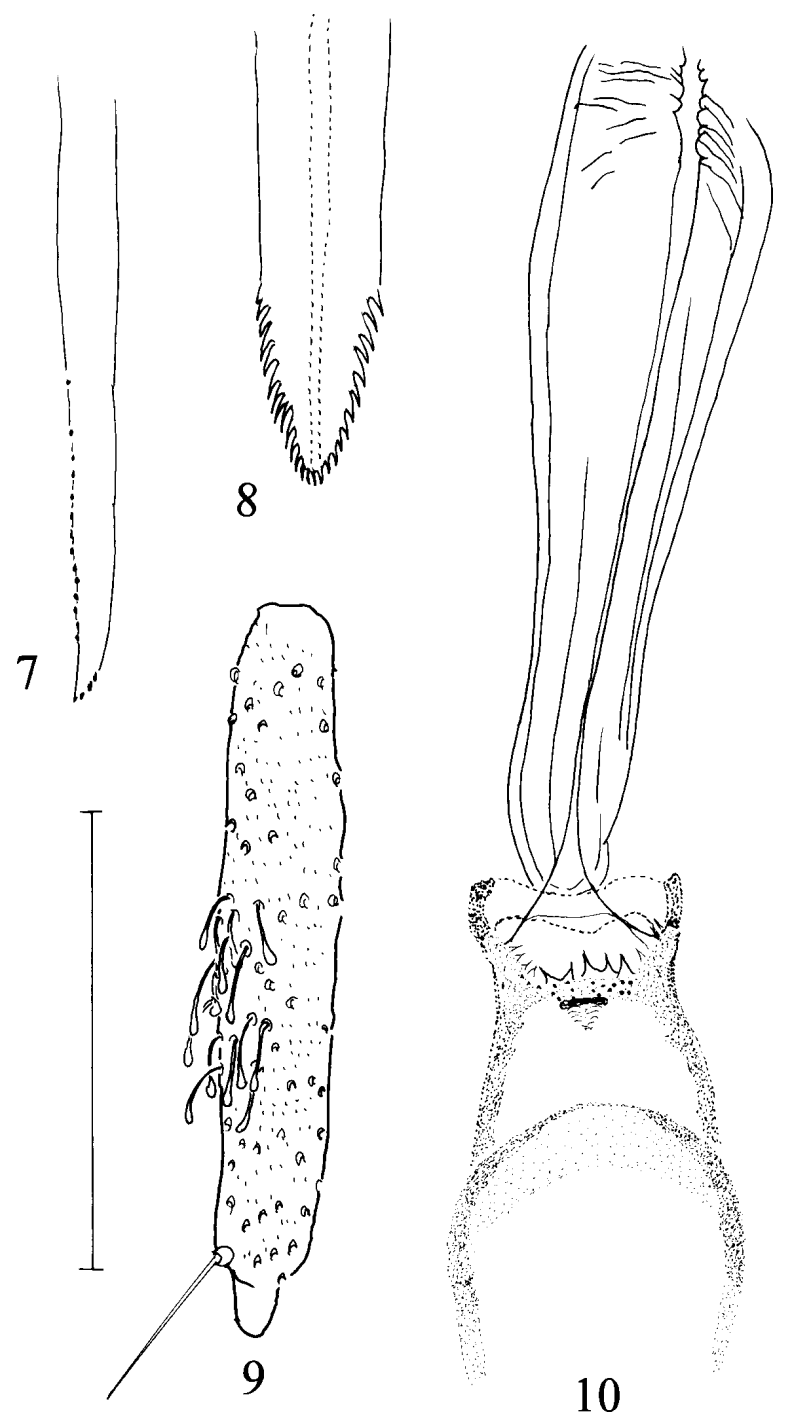

Pintomyia (Pifanomyia) aldafalcaoae sp. nov. Allotype female Fig. 7: maxilla's lacinia. Fig. 8: hypopharynx. Fig. 9: palpomere III. Fig. 10: cibarium. $\mathrm{Bar}=100 \mu \mathrm{m}$ 

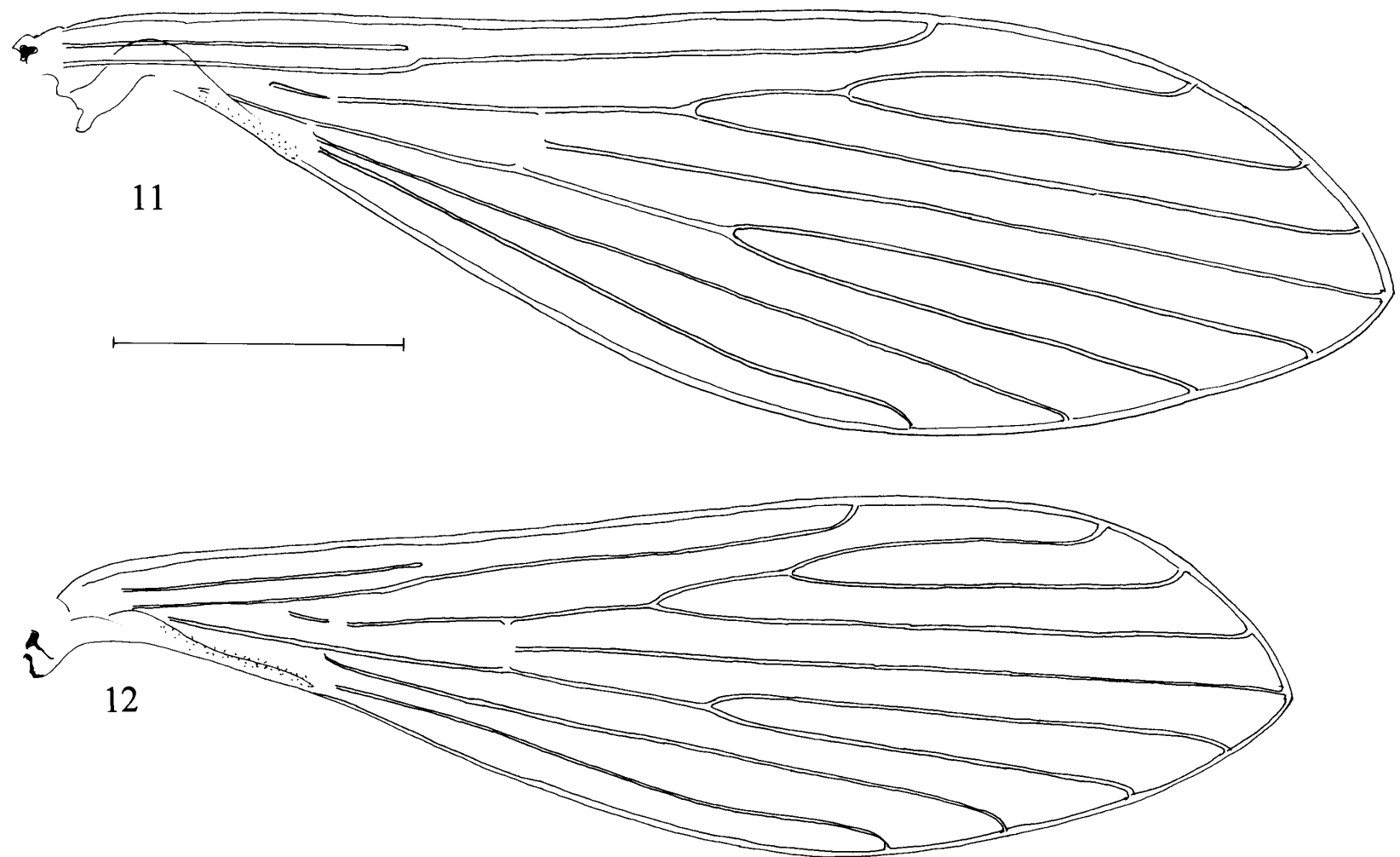

Wings of Pintomyia (Pifanomyia) aldafalcaoae sp. nov. - Fig. 11: allotype female. Fig. 12: holotype male. Bar $=500 \mu \mathrm{m}$

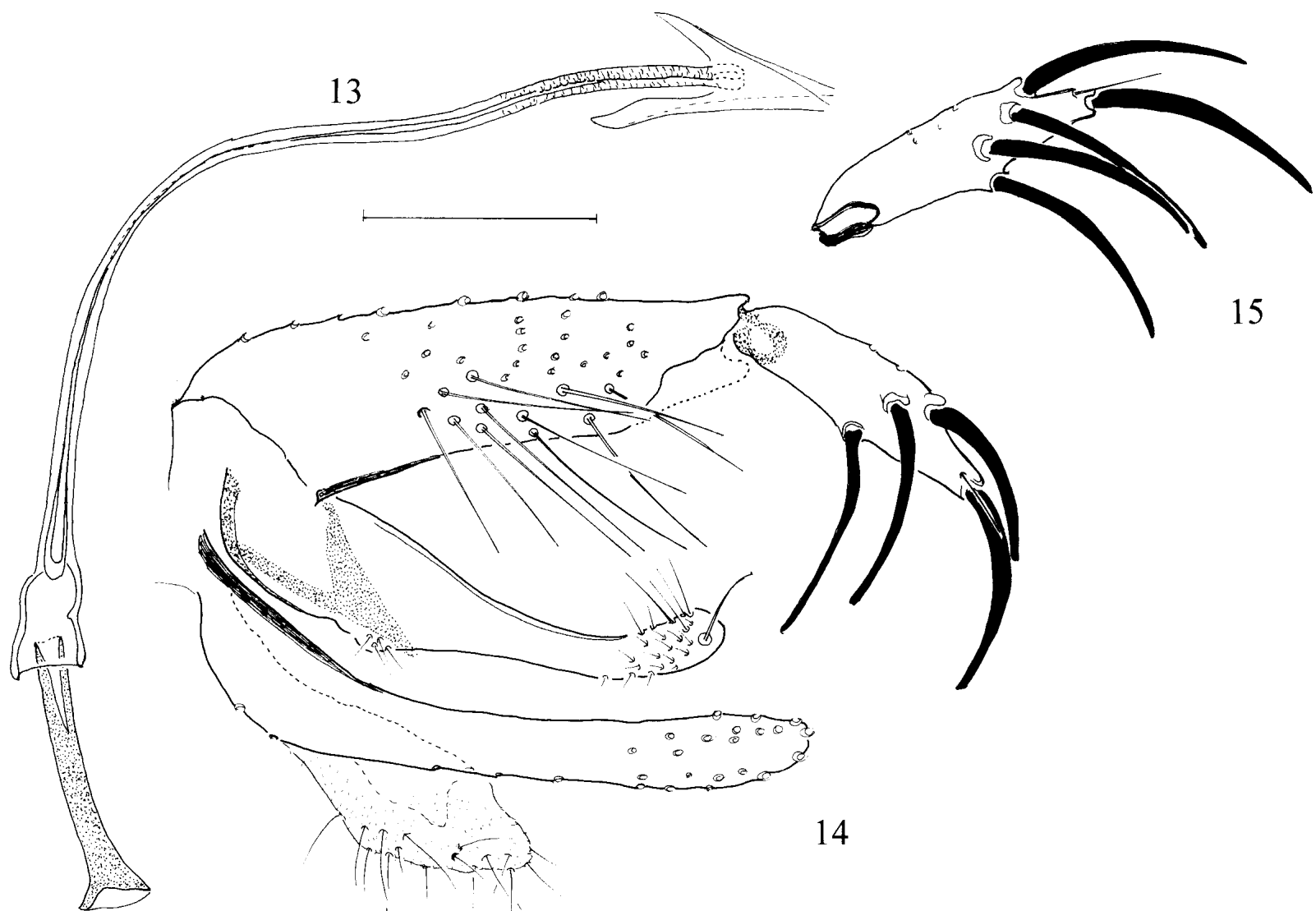

Pintomyia (Pifanomyia) aldafalcaoae sp. nov. holotype male - Fig. 13: aedeagus, genital pump and filaments. Fig. 14: terminalia. Fig. 15: the other gonostyle. Bar $=100 \mu \mathrm{m}$ 


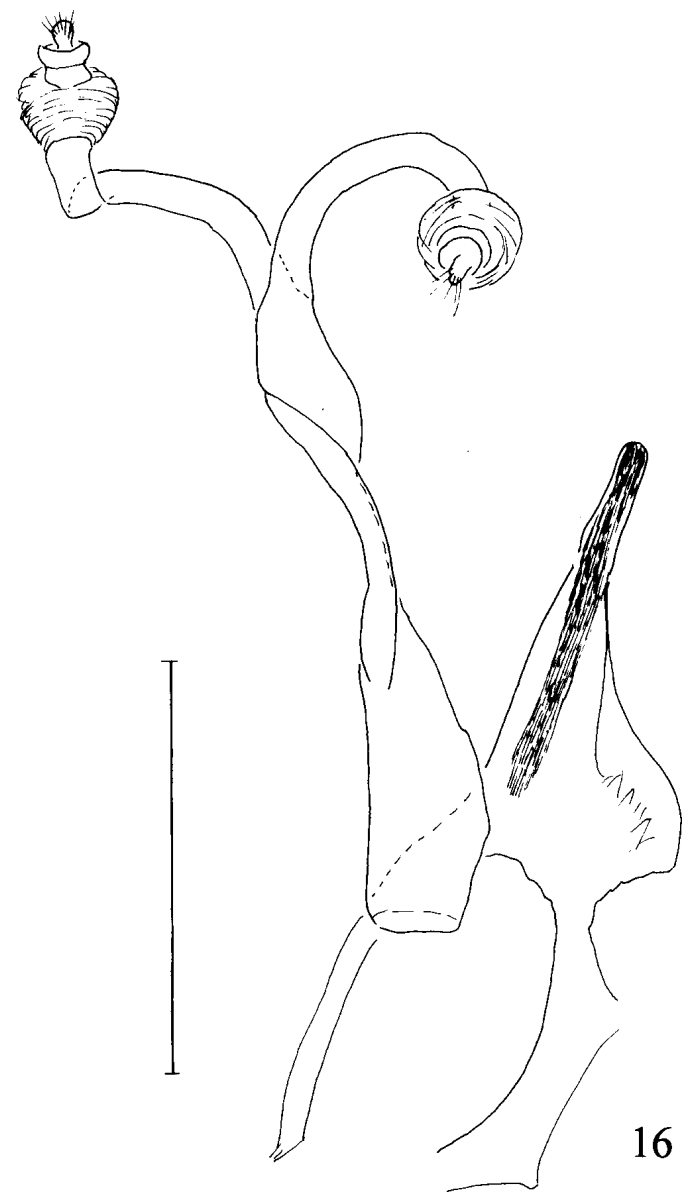

Fig. 16: Pintomyia (Pifanomyia) aldafalcaoae sp. nov. allotype female. Genital fork and spermathecae. Bar $=100 \mu \mathrm{m}$

middle of the structure; the internal one implanted on a prominent tubercle. Gonocoxite 275 long x 108 wide (255, $275 \times 100,107 ; n=2$ ) with three tufts of long setae. The basal tuft with $c a .40$ sinuous setae; the median with 6-7 semi-foliaceous setae and the apical tuft with $c a .30$ straight setae. Paramere (Figs 24, 26): dorsal margin length $227(210,230 ; n=2)$ and the ventral margin length 280 $(280 ; \mathrm{n}=2)$; the median part of the dorsal margin with evident concavity and in its apex presents a little tubercle with five setae; margin ventral with a pre-apical protuberance and a little tubercle covered with short setae. Aedeagus (Fig. 26) conical, dorsal margin length 112 (108, $112 ; n=2)$ and the ventral margin length $75(95 ; n=2)$. Lateral lobe ( 425 long $\times 20$ wide in the middle/ 45 at the apex) $(415,430 \times 20 / 45,20 / 48 ; n=2)$. Genital pump: 167 $(158 ; \mathrm{n}=2)$ long; piston length $135(125,130 ; \mathrm{n}=2)$ and chamber length $60(60,55 ; n=2)$. Genital filament length $627(573,620 ; n=2)$ or $3.75(3.62,3.92 ; n=2)$ times length of genital pump. Tip of genital filament simple, but slightly widened (Fig. 23). Cercus $245(230,238 ; n=2)$ long.

Collection dates and deposition of type material. Holotype male and one paratype male: Montebello, Antioquia Department, Colombia, 31.3.1997. One paratype male same locality as holotype, 31.3.1998. All three captured by $\mathrm{M}$ Wolff with sticky traps (paper strips impregnated with

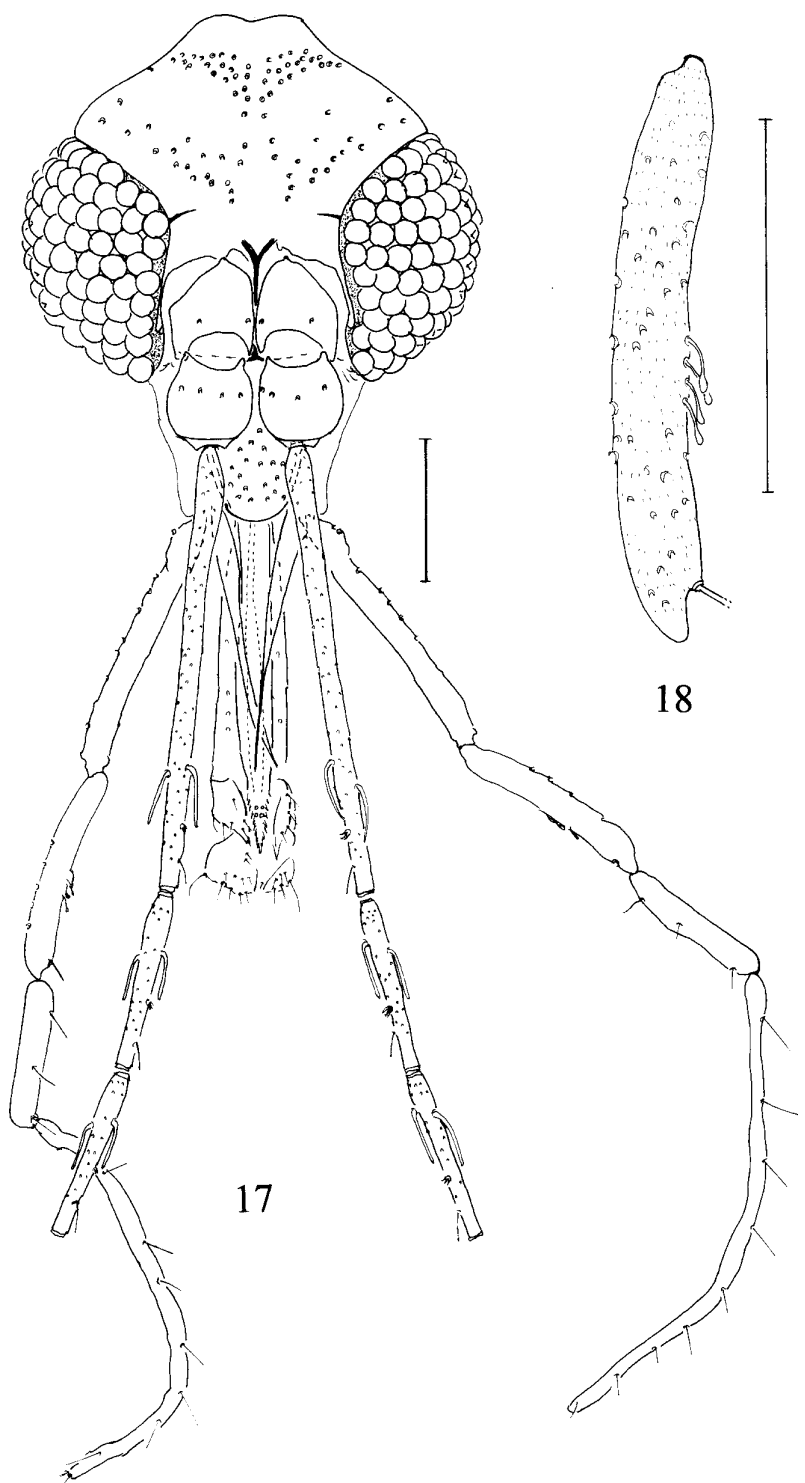

Pintomyia (Pifanomyia) antioquiensis sp. nov. Holotype male Fig. 17: head. Fig. 18: palpomere III. Bars $=100 \mu \mathrm{m}$

castor oil) and deposited in the entomological collection of the Department of Biology, University of Antioquia, Colombia.

Locality type similar to $P$. (P.) limafalcaoae sp. nov.

\section{TAXONOMIC DISCUSSION}

The taxon Pifanomyia Ortiz \& Scorza, 1963 was proposed as a subgenus of the genus Phlebotomus Rondani, 1840 consisting of the species of group serrana Barretto, 1962. This group of species and four other groups: vespertilionis, vesicifera, christophei and verrucarum were included in the subgenus Coromyia Barretto, 1962 of the genus Lutzomyia França, 1924 by Barretto (1962). Theodor (1965) and Lewis et al. (1977) included the species group verrucarum, consisting of the series verrucarum Fairchild, 1955 and serrana, within the genus Lutzomyia. Vianna Martins et al. (1978) considered the verrucarum species group to consist only members of 


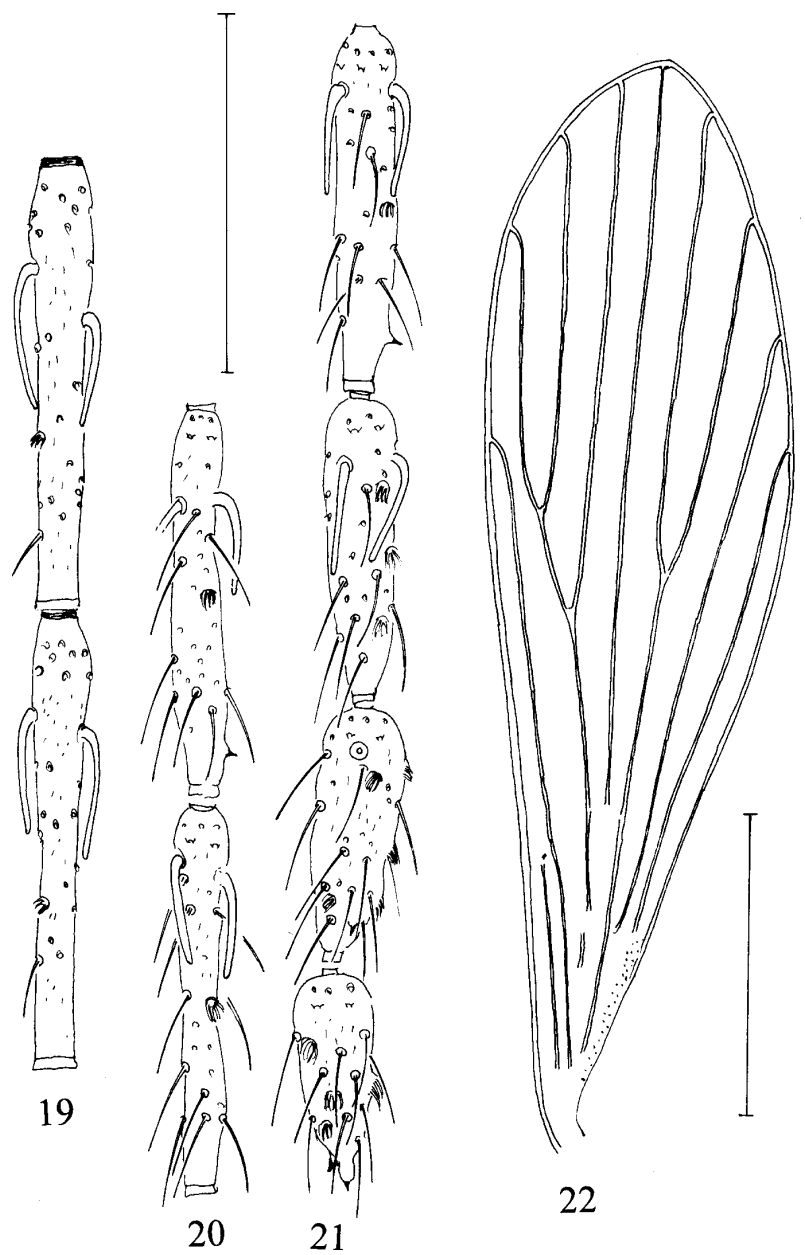

Pintomyia (Pifanomyia) antioquiensis sp. nov. Holotype male Fig. 19: antennomere IV-V. Fig. 20: antennomere XI-XII. Fig. 21: antennomere XIII-XVI. Bar $=100 \mathrm{~mm}$. Fig. 22: wing. Bar $=500 \mu \mathrm{m}$

the series verrucarum and the subgenus Pifanomyia as originally proposed, but within the genus Lutzomyia. Young and Duncan (1994) admitted group verrucarum and eliminated the series of species. Galati et al. (1995) amplified the subgenus Pifanomyia to include the series evansi, monticola, verrucarum and townsendi in the genus Lutzomyia and following Galati (1995) included two other series: pacae and pia and considered that all belonged within the genus Pintomyia Costa Lima, 1932, together with the subgenus Pintomyia, s. str.

Both sexes of this genus may be characterized as follows: 5th palpomere longer than 3rd; on this palpomere, Newstead's spines occur between the median and preapical regions; ventrocervical sensillae present and the setae on the anterior margin of katepisternum may occur. Male: flagellomere with short ascoids, those on AIV, commonly not passing the middle of the segment; gonostyle with three, four or five spines and presence (with some exceptions) of the pre-apical seta; gonocoxite with or without tufts of setae; lateral lobes with round apices and thinner than gonocoxite; simple paramere; presence of tergal papillae (except in series townsendi) at least on some tergites. Female: ratio between lengths 2 nd palpomere/ palpus > 0.16:1.0; ascoids on the AIV reaching the subapical region of the segment; hypopharynx with well delimited and deep teeth; lacinia with external teeth disposed in a single and longitudinal row, cibarium with four (sometimes five or six) posterior horizontal teeth and the anterior (vertical) teeth in one or two transversal rows, complete sclerotised arch; Tergite VIII with or without setae; spermathecae with long common duct, the individual ducts may or may not be sclerotised, the body predominantly vesicular with or without wrinkled aspect, apical ring and distinct terminal knob. The subgenus Pifanomyia is distinguished from Pintomyia, s. str, in both sexes by the absence of spines on the hind femur and in the females by the spermathecae which present an apical ring, distinct knob and unsclerotised individual ducts.

In the male, the presence on the gonostyle of one major apical spine, the subapical seta and extra external spine and in the female the wrinkled vesicular aspect of the spermatheca with a much narrower apical ring, long common duct and shorter individual ducts, lead us to consider P. limafalcaoae sp. nov. as belonging to the series pia. This series had hitherto been constituted of seven species: P. pia (Fairchild \& Hertig, 1961), P. reclusa (Fernandez \& Rogers, 1991), P. suapiensis (Le Pont, TorrezEspejo \& Dujardin, 1997), P. tihuiliensis (Le Pont, TorrezEspejo \& Dujardin, 1997), P. tocaniensis (Le Pont, TorrezEspejo \& Dujardin, 1997), P. torrealbai (Vianna Martins, Fernandez \& Falcão, 1979) and P. valderramai (Cazorla, 1988). With the exception of $P$. pia, all these species are known by specimens of only one of the sexes; $P$. suapiensis, $P$. tihuiliensis and $P$. tocaniensis by the female and $P$. reclusa, $P$. torrealbai and $P$. valderramai by the male.

$P$. pia was included in the species group oswaldoi of the genus Lutzomyia by Theodor (1965) and by Cazorla (1988), to which P. valderramai was also considered to belong. Young and Duncan (1994) included this latter species in this group, but $P$. pia was considered to be an ungrouped species, as was $P$. torrealbai. Vianna Martins et al. (1978) included P. pia in isolated or aberrant species and Vianna Martins et al. (1979) consider P. torrealbai as an aberrant species. $P$. reclusa was included in the subgenus Helcocyrtomyia Barretto, 1962 by Fernandez and Rogers (1991) and Young and Duncan (1994). Le Pont et al. (1997) consider $P$. suapiensis, $P$. tihuiliensis and $P$. tocaniensis as incertae sedis and suggest that this three species may, together with $P$. pia, constitute another series of the subgenus Pifanomyia.

The male and the female of this new species may be distinguished from the others of the series pia by the characteristics in the identification key presented below:

Males

1 Tuft of the gonocoxite sparse and situated on the median 3rd

the

Tuft of the gonocoxite compact and situated on the basal-median part...

2(1) Dorsal margin of the paramere almost straight and the setae on the apical $3 \mathrm{rd}$..... P. pia 


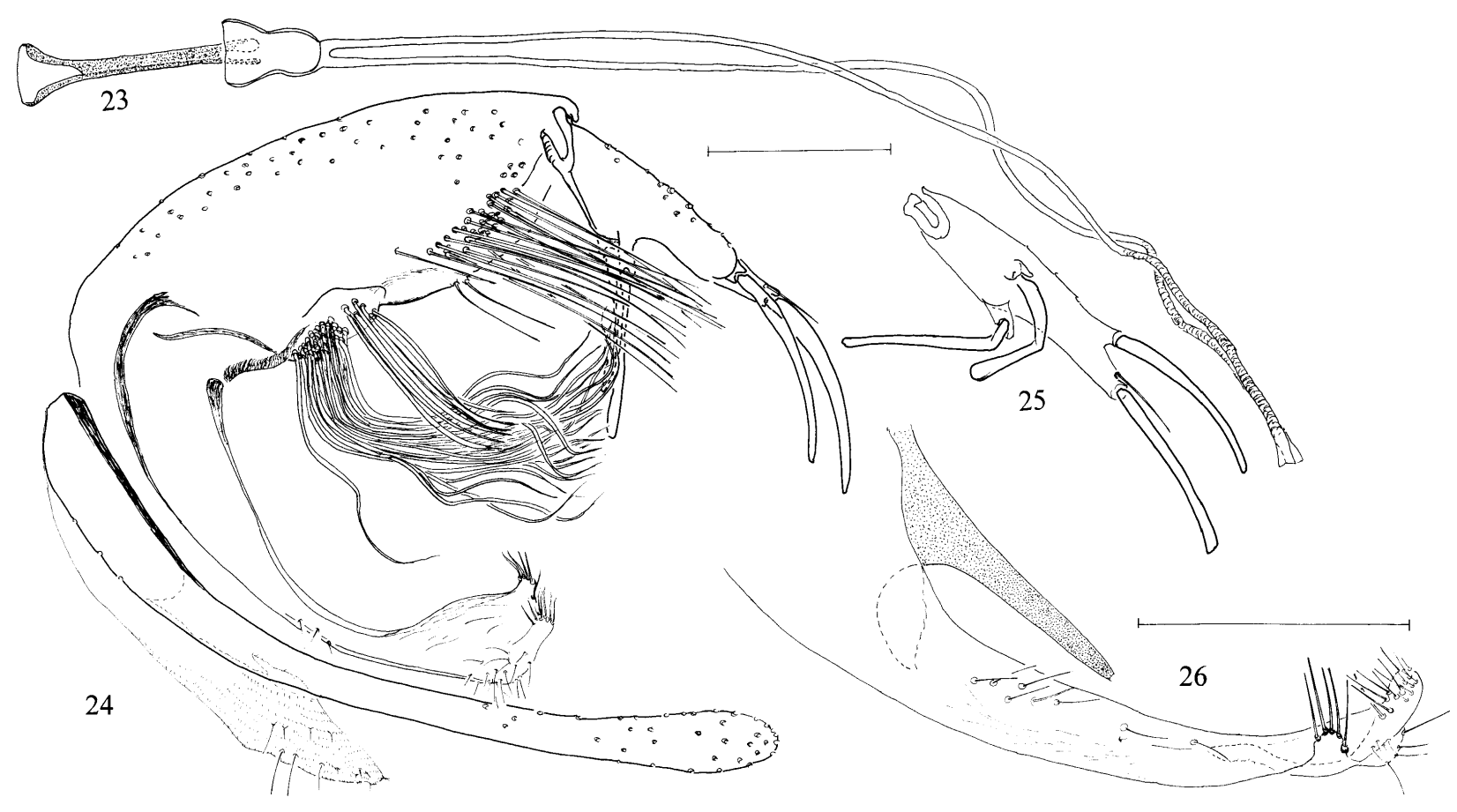

Pintomyia (Pifanomyia) antioquiensis sp. nov. holotype male - Fig. 23: genital pump and filaments. Fig. 24: terminalia. Fig. 25: the other gonostyle. Fig. 26: aedeagus and the other paramere. Bars $=100 \mu \mathrm{m}$

Dorsal margin of the paramere curve and the apical setae on the apical 5th .......... P. limafalcaoae sp. nov. 3(1) Labroepipharynx ca. $280 \mu \mathrm{m}$; AIII $c a .350 \mu \mathrm{m}$ L.................................................... P. reclusa 4(3)Tuft of the gonocoxite with ca. 10 setae

Tuft of the gonocoxite with $c a$. 17-19 setae P. torrealbai P. valderramai

Females

1 Labroepipharynx more than $350 \mu \mathrm{m}$. ....2 Labroepipharynx smaller than or equal to $310 \mu \mathrm{m} . . . . . .3$ 2(1) Pleurae all brown P. pia Pleurae brown only in the basal region ...P. tihuiliensis

3(1) Pleurae all brown .... P. limafalcaoae sp. nov. Pleurae partially brown or completely pale

4(3) Pleurae completely pale Pleurae brown in its basal part P. tocaniensis

The Pintomyia (Pifanomyia) antioquiensis sp. nov. presents papilla in $\mathrm{AV}$; gonocoxite with a sclerotised band on the basal ventral margin and presence of tufts of setae; gonostyle with four spines, with the internal one implanted before or in the middle of the structure; presence of tergal papillae in some tergites may be included, according to Galati (1995), into the series verrucarum. Based on these characteristics eight species are included in this series: P. andina (Osorno, Osorno-Mesa \& Morales, 1972), P. aulari (Feliciangeli, Ordoñez \& Manzanilla, 1984), P. cajamarcensis (Galati, Cáceres \& Le Pont, 1995), $P$. columbiana (Ristorcelli \& Van Ty, 1941), P. deorsa (Pérez,
Ogusuku, Monje \& Young, 1991), P. disiuncta (Morales, Osorno \& Osorno-Mesa, 1974), P. moralesi (Young, 1979) and $P$. verrucarum (Townsend, 1913).

The male of $P$. antioquiensis may be distinguished from the other species of the series verrucarum by the characteristics present in the following identification key:

1 Gonocoxite with single basal tuft of setae ................. 2

Gonocoxite with two or more tufts of setae ................ 3

2(1) Aedeagus arched, which apex is turned downwards, just as a goose's head ........................................ deorsa Aedeagus simple and conical ............... P. columbiana

3(1) Gonostyle with the internal spine implanted in accentuated tubercle 4 Gonostyle with the internal spine implanted in discrete tubercle ............................................. 7

4(3) Gonocoxite with three tufts of setae ............................ 5 Gonocoxite with two tufts of setae ...................................6

5(4) Gonostyle without subapical seta; the apical part of paramere with incipient lobe; setae of the basal tuft's gonocoxite not exceeding the paramere's apex

P. moralesi

Gonostyle with subapical seta; the apical part of paramere with two evident lobes; setae's apex of the basal tuft's gonocoxite exceeding the paramere's apex P. antioquiensis sp. nov.

6(4) Apex of the inferior external spine of gonostyle truncated and with slight expansion P. andina Apex of the inferior external spine of gonostyle pointed. P. aulari

7(3) Gonostyle with columnar aspect, the distance between the external spines greater than twice the distance of 
the superior external from the apical spines. .8 Gonostyle with the distance between the external spines similar to the distance between superior external and the apical spines P. verrucarum $8(7)$ Dorsal margin's paramere strongly concave and with apical fringe of long setae P. cajamarcensis Dorsal margin's paramere with slight concavity and without apical fringe of setae P. disiuncta

Etymology. By conferring the name $P$. (P.) limafalcaoae we pay tribute to researcher Alda Lima Falcão of the Centro de Pesquisa René Rachou, Fundação Oswaldo Cruz, Belo Horizonte, Brazil, for her great contribution to our knowledge of American sand flies. The other new species takes its name from the Department of Antioquia, Colombia, where the species was captured.

The association of the sexes of $P$. (P.) limafalcaoae was based on the capture of males and females in the same place, on the compatibility of genital characteristics and similarities of the extra genital characteristics.

\section{REFERENCES}

Barretto MP 1962. Novos subgêneros de Lutzomyia França, 1924 (Diptera, Psychodidae, subfamília Phlebotominae). Rev Inst Med Trop São Paulo 4: 91-110.

Cazorla D 1988. A new species of Lutzomyia (Diptera: Psychodidae) from Venezuelan Andes Region. Rev Brasil Biol 48: 607-610.

Fernández R, Rogers E 1991. Lutzomyia reclusa (Diptera: Psy- chodidae, Phlebotominae) nueva especie de la vertiente occidental peruana. Rev Per Entomol 33: 129-131.

Forattini OP 1973. Entomologia Médica. IV. Psychodidae. Phlebotominae. Leishmanioses. Bartonelose, Edgard Blücher Ltda., São Paulo, 658 pp.

Galati EAB 1995. Phylogenetic systematics of Phlebotominae (Diptera, Psychodidae) with emphasis on American groups. Bol Dir Malariol San Amb 35(Supl. 1): 133-142.

Galati EAB, Cáceres AG, Le Pont F 1995. Descrições de duas espécies novas de Phlebotominae (Diptera, Psychodidae) e considerações sobre o subgênero Pifanomyia Ortiz \& Scorza. Revta Bras Entomol 39: 431-446.

Le Pont F, Torrez-Espejo M, Dujardin P 1997. Phlébotomes de Bolivie: description de quatre nouvelles espéces de Lutzomyia (Diptera: Psychodidae). Ann Soc Entomol Fr (NS)33: 55-64.

Lewis DJ, Young DG, Fairchild GB, Minter DM 1977. Proposals for a stable classification of the sandflies (Diptera: Psychodidae). Syst Entomol 2: 319-332.

Theodor O 1965. On the classification of American Phlebotominae. J Med Entomol 2: 171-197.

Vianna Martins A, Fernández RO, Falcão AL 1979. Flebotomíneos da Venezuela: Lutzomyia torrealbai $\mathrm{n}$. sp. do Estado Trujillo. (Diptera, Psychodidae). Rev Brasil Biol 39: 431-433.

Vianna Martins A, Williams P, Falcão AL 1978. American Sand Flies, Academia Brasileira de Ciências, Rio de Janeiro, 195 $\mathrm{pp}$.

Young DG, Duncan MA 1994. Guide to the identification and geographic distribution of Lutzomyia sand flies in Mexico, the West Indies, Central and South America (Diptera: Psychodidae). Mem Amer Entomol Inst 54: 1-881. 